\title{
Review Article \\ Therapeutic Approaches to Limit Hemolysis-Driven Endothelial Dysfunction: Scavenging Free Heme to Preserve Vasculature Homeostasis
}

\author{
Francesca Vinchi and Emanuela Tolosano \\ Department of Molecular Biotechnology and Health Sciences, Molecular Biotechnology Center, University of Torino, \\ Via Nizza 52, 10126 Torino, Italy \\ Correspondence should be addressed to Emanuela Tolosano; emanuela.tolosano@unito.it
}

Received 1 March 2013; Revised 29 April 2013; Accepted 14 May 2013

Academic Editor: John D. Belcher

Copyright ( 2013 F. Vinchi and E. Tolosano. This is an open access article distributed under the Creative Commons Attribution License, which permits unrestricted use, distribution, and reproduction in any medium, provided the original work is properly cited.

\begin{abstract}
Hemolysis results in the release of hemoglobin and heme into the bloodstream and is associated with the development of several pathologic conditions of different etiology, including hemoglobinopathies, hemolytic anemias, bacterial infections, malaria, and trauma. In addition, hemolysis is associated with surgical procedures, hemodialysis, blood transfusion, and other conditions in which mechanical forces can lead to red blood cell rupture. Free plasma hemoglobin and heme are toxic for the vascular endothelium since heme iron promotes oxidative stress that causes endothelial activation responsible for vasoocclusive events and thrombus formation. Moreover, free hemoglobin scavenges nitric oxide, reducing its bioavailability, and heme favours ROS production, thus causing oxidative nitric oxide consumption. This results in the dysregulation of the endothelium vasodilator:vasoconstrictor balance, leading to severe vasoconstriction and hypertension. Thus, endothelial dysfunction and impairment of cardiovascular function represent a common feature of pathologic conditions associated with hemolysis. In this review, we discuss how hemoglobin/heme released following hemolysis may affect vascular function and summarise the therapeutic approaches available to limit hemolysis-driven endothelial dysfunction. Particular emphasis is put on recent data showing the beneficial effects obtained through the use of the plasma heme scavenger hemopexin in counteracting heme-mediated endothelial damage in mouse models of hemolytic diseases.
\end{abstract}

\section{Hemolytic Diseases}

Hemolysis is a pathologic condition characterized by the increased release of hemoglobin $(\mathrm{Hb})$ and heme. Several human diseases and pathologic situations with different etiology are associated with hemolysis including paroxysmal nocturnal hemoglobinuria (PNH), sickle-cell disease (SCD), thalassemias, hereditary spherocytosis and stomatocytosis, microangiopathic hemolytic anemias, pyruvate kinase deficiency, $\mathrm{ABO}$ mismatch transfusion reaction, paroxysmal cold hemoglobinuria, severe idiopathic autoimmune hemolytic anemia, infection-induced anemia, and malaria $[1,2]$. Moreover, several recent studies indicate that hemolysis is also associated with procedures including hemodialysis, blood transfusion, and cardiac bypass in which mechanical shearing forces may lead to red blood cell rupture [3].
During hemolysis, red blood cells release $\mathrm{Hb}$, which form stable complexes with the acute phase protein haptoglobin (Hp) [4]. The Hp-Hb complexes are cleared from circulation by monocytes and macrophages expressing the scavenger CD163 receptor. The function carried out by Hp is crucial, as demonstrated by studies on animal models and humans (recently reviewed in Schaer et al. [5]). When Hp's buffering capacity is overwhelmed, $\mathrm{Hb}$ undergoes a rapid conversion to metHb, liberating heme. Ferriheme then binds to albumin and other plasma components including lipoproteins and is subsequently transferred to hemopexin (Hx) [6, 7]. Hp and $\mathrm{Hx}$, by binding with high affinity $\mathrm{Hb}$ and heme, respectively, block their prooxidant effects $[4,8]$. Heme that escapes the binding to Hx enters into cells and is neutralized by heme oxygenases (HO). HO degrades the heme ring into iron, carbon monoxide ( $\mathrm{CO}$ ), and biliverdin, thus exerting primary 
anti-inflammatory, antioxidant, and antiapoptotic effects [2, 9-11]. In mammals, biliverdin is then rapidly converted into bilirubin by biliverdin reductase and excreted into the bile [12]. To date, three isoforms of $\mathrm{HO}$ have been identified, $\mathrm{HO}-1, \mathrm{HO}-2$, and HO-3, encoded by three different genes. The expression, distribution, and regulation, of HO-1, HO2 and HO-3 differ among cell types and tissues. HO-3 has poor heme degrading capacity [13] and is now considered a pseudogene, whereas $\mathrm{HO}-1$ and $\mathrm{HO}-2$ are the actual hemedegrading enzymes [14]. HO-1 levels have been demonstrated to be low under normal physiological conditions but highly inducible by several stimuli including heme and other oxidant agents, while $\mathrm{HO}-2$ has been described as a constitutively expressed enzyme $[2,15,16]$. The activity of $\mathrm{HO}$ is strictly associated with the function of ferritins and cytosolic proteins that sequester iron coming from heme catabolism. Ferritins are composed of varying ratios of two different subunits: H-ferritin and L-ferritin. H-ferritin is endowed with a ferroxidase activity and is essential for iron incorporation into the core of large L-ferritin and $\mathrm{H}$-ferritin complexes [17].

In hemolytic diseases, cell-free plasma $\mathrm{Hb}$ and heme overwhelm homeostatic systems in place to remove them. As a consequence, various hemolytic diseases of different etiology share hemoglobinemia-related sequelae, characterized by endothelial dysfunction, thrombosis, vascular disease, and renal failure [14]. Observations from the clinical administration of artificial, purified, and recombinant $\mathrm{Hb}$ solutions have provided support for the causal relationship between excess cell-free $\mathrm{Hb} /$ heme in the bloodstream, symptoms, and cardiovascular events. In particular, pulmonary hypertension $(\mathrm{PH})$ is emerging as one of the leading causes of morbidity and mortality in patients with hemolytic anemias, including $\mathrm{SCD}$, thalassemia, PNH, hereditary spherocytosis and stomatocytosis, microangiopathic hemolytic anemias, pyruvate kinase deficiency, and possibly malaria [18-26].

In the last decades, medical advances in the management of patients suffering from SCD, thalassemia and other hemolytic anemias have led to significant increase in life expectancy [27]. Improved public health with neonatal genetic screening, parental and patient education, advances in red cell transfusion medicine safety, aggressive iron chelation therapy, penicillin prophylaxis for children under 6 years of age, immunization, and hydroxyurea therapy has all likely contributed to this effect on longevity [28]. Now, as a generation of patients with SCD and thalassemia ages, new chronic vascular complications of these hemoglobinopathies develop.

Here, we first discuss the causal relationship between hemolysis and endothelial dysfunction, and then we focus on different therapeutic approaches aimed at counteracting hemolysis-driven adverse effects on the vasculature.

\section{Hemolysis and Endothelial Dysfunction}

Chronic intravascular hemolysis is associated with prooxidant and proinflammatory stresses and with a state of endothelial dysfunction characterized by reduced nitric oxide
(NO) bioavailability [29-31] and coagulopathy [32], leading to vasomotor instability and ultimately to vasculopathy [33]. The causal link between endothelial dysfunction and hemolysis has been well documented. Endothelial dysfunction is the earliest clinically detectable stage of cardiovascular disease characterized by a shift of the actions of the endothelium toward reduced vasodilation, a proinflammatory state, and prothrombotic properties [29, 34-37].

The entire circulatory tree is lined by a single epitheliallike layer of vascular endothelial cells (ECs). Although ECs exhibit characteristics that vary with anatomic location, both by organ system and by vessel type (e.g., artery, arteriole, capillary, venule, and vein), all ECs share common features that distinguish them from other cell types and allow them to perform critical homeostatic functions. Key homeostatic functions include retaining blood fluid, regulating blood flow, regulating macromolecule and fluid exchange with the tissues, preventing leukocyte activation, and aiding in immune surveillance for pathogens [38]. Injury or cell death impairs or prevents conduct of these activities, resulting in dysfunction. Most endothelial cell death is apoptotic, involving activation of caspases $[39,40]$.

Stimuli that can cause endothelial injury or death include oxidative stress, endoplasmic reticulum stress, metabolic stress, and genotoxic stress, as well as pathways of injury mediated by the innate and adaptive immune systems [41]. Hemolysis is directly involved in endothelial injury, and recent data suggest that chronic intravascular hemolysis is associated with a state of endothelial dysfunction, leading to hypertension $[29,30,42,43]$. Some of these vascular effects, predisposing to hemolysis-associated hypertension, are linked to cytotoxic, proinflammatory, and prooxidant effects of ironcontaining $\mathrm{Hb}$ and heme, whereas others are related to $\mathrm{NO}$ scavenging by excess plasma $\mathrm{Hb}[18,44]$.

2.1. Hemolysis-Driven Oxidative Stress and Endothelial Activation. Because of chronic hemolysis, hemolytic patients are exposed to reactive oxygen species (ROS) generation catalyzed by heme-derived redox-active iron, the vessel wall being the primary exposed tissue. In the last years, it has been demonstrated that oxidative stress and inflammation directly contribute to vasoocclusive events and thrombus formation in hemolytic patients. Belcher and coauthors proposed that $\mathrm{Hb}$, heme, and iron derived from hemolytic red blood cells promote excessive ROS production, leading to endothelial activation and adhesion molecule expression on the vessel wall, which in turn favour the adhesion of red blood cells and leukocytes to the endothelium, thus resulting in vascular instability and eventually vasoocclusion $[42,43]$. Intravital microscopy studies on SCD mice demonstrated the critical role of adhesion molecules, such as P-selectin, VCAM-1, and ICAM-1, for the interaction of sickle red blood cells and leukocytes with the vessel wall and that blockade or knockout of these molecules prevents either cytokineor hypoxia-induced stasis. In $\beta$-thalassemia, studies have reported increased levels of vascular adhesion molecules, indicating that endothelial dysfunction participates in thrombotic events. 
2.2. Hemolysis-Mediated NO Bioavailability Reduction. In hemolytic patients, hemolysis-driven endothelial dysfunction is characterized by reduced NO bioavailability and NO resistance. This leads to dysregulation of the endotheliumderived vasodilator:vasoconstrictor system, thus causing severe vasoconstriction $[19,33,45,46]$.

$\mathrm{NO}$ is a potent endogenous vasodilator produced in endothelium by the endothelial NO synthase (NOS) enzyme, thanks to the oxygen-dependent conversion of L-arginine to citrulline. Once produced, NO can diffuse from the endothelium to adjacent smooth muscle where it binds avidly to the heme moiety of soluble guanylate cyclase. This activates the enzyme, which in turn converts GTP to cGMP, activating cGMP-dependent protein kinases and producing vasodilation. In addition to this vasodilation, which is tonic in nature and controls approximately $25 \%$ of our resting blood flow, NO promotes general vascular homeostasis and health [47]. NO tonically downregulates transcription of endothelial adhesion molecule genes, such as VCAM-1, ICAM-1, Pselectin, and E-selectin [48]. Nitric oxide also inhibits platelet activation, tissue factor expression, and thrombin generation [49]. NO modulates the expression of endothelin receptors (promoting a vasodilator effect by increase in endothelialendothelin receptor B expression) and decreases expression of endothelin 1, a potent mitogen and vasoconstrictor [50].

It is now well accepted that during hemolysis, cell-free oxyHb in the plasma functions as an $\mathrm{NO}$ scavenger, producing metHb and nitrate $\left(\mathrm{NO}^{3-}\right)$ in a reaction that is fast and irreversible [5]. Normally, in the absence of hemolysis, the amount of $\mathrm{NO}$ scavenged by $\mathrm{Hb}$ is greatly limited by the $\mathrm{Hb}$ sequestration within the red blood cell plasma membrane. This sequestration produces major bulk diffusional barriers to NO, which include an unstirred layer around the red blood cell, an intrinsic membrane permeability barrier to $\mathrm{NO}$, and a cell-free zone along the endothelium in laminar flowing blood. These combined barriers reduce the reaction rate of NO with intracellular $\mathrm{Hb}$ by approximately 1000fold [51]. In hemolytic disorders, the diffusional barriers created by the red cell membrane that limits NO reactions with $\mathrm{Hb}$ are disrupted, and the cell-free plasma $\mathrm{Hb}$ destroys $\mathrm{NO}$ at a rate of 1000 -fold faster than intraerythrocytic $\mathrm{Hb}$, resulting in abnormally high rates of NO consumption, which produces a state of resistance to $\mathrm{NO}$ activity [37, 46, 51, 52]. Consequently, smooth muscle guanylyl cyclase is not activated, and vasodilation is impaired. In support of this mechanism, plasma from patients with SCD contains oxyHb, which reacts with and consumes micromolar quantities of $\mathrm{NO}$ and inhibits forearm blood flow responses to NO donor infusions [34]. Remarkably, kinetic models suggest that levels of plasma $\mathrm{Hb}$ as low as $1 \mu \mathrm{M}$ have the potential to impair endothelial NO signaling, and heme concentrations as low as $6 \mu \mathrm{M}$ have been found to impair NO-dependant vasodilation in vivo in SCD patients [34]. Similar effects of hemolysis on NO bioavailability and endothelial function have recently been reported in malaria [53].

In hemolytic disorders, consumption/inactivation of NO is accelerated due not only to $\mathrm{Hb}$ scavenging but even to chronic oxidative stress promoted by free heme. In these patients, heme-induced ROS production is implicated in NO consumption and formation of peroxynitrite and in NOS uncoupling $[18,54]$. Finally, hemolysis also releases arginase1 from red blood cells that react with NOS substrate, Larginine, to form ornithine, effectively reducing L-arginine availability for NO production by endothelial NOS. This results in a perpetual activation of the vascular endothelium because of chronic oxidative stress, hemolysis, and reduced NO [55].

2.3. Hemolysis-Induced Thrombosis. In addition to the toxic effects above reported, excessive plasma $\mathrm{Hb}$ and heme may contribute to platelet activation and thrombosis. The infusion of cross-linked $\mathrm{Hb}$ increases platelet aggregation and adhesion in vivo on prothrombotic surfaces such as an injured vessel wall. Administration of heme in healthy volunteers is associated with thrombophlebitis, demonstrating that heme can cause vascular inflammation followed by vascular obstruction in vivo [56,57]. Interestingly, the addition of cellfree $\mathrm{Hb}$ to human serum at concentrations of 0.2 to $2.0 \mathrm{~g} / \mathrm{dL}$ causes a dose-dependent inhibition of the metalloprotease ADAMTS13, an enzyme critical in limiting platelet thrombus formation. The major untoward effects of plasma $\mathrm{Hb}$ and heme on platelet function are most likely mediated by the scavenging of NO. NO interacts with components of the coagulation cascade to downregulate clot formation. In particular, NO has been shown to inhibit platelet aggregation, induce disaggregation of aggregated platelets, and inhibit platelet adhesion through increasing cGMP levels [58]. In fact, NO donor drugs (S-nitrothiols) that increase systemic levels of NO have been shown to inhibit platelet aggregation [59]. Conversely, $\mathrm{NO}$ scavenging by $\mathrm{Hb}$ or the reduction of $\mathrm{NO}$ generation by the inhibition of arginine metabolism results in an increase in platelet aggregation [34]. In animal models, reduction of NO causes increases in fibrin split products and thrombin-antithrombin complexes leading to significant fibrin deposition and thrombus formation. Moreover, in a patient with L-arginine deficiency, reduced NO production is associated with increased thrombin-antithrombin complexes and fibrin split products, while reversal of NO deficiency with L-arginine causes a reduction in intravascular coagulopathy $[33,35,60,61]$.

The adverse effects of hemolysis on the vasculature are summarized in Figure 1.

In the next two sections, we report the "state of the art" on the molecules used to limit $\mathrm{Hb} / \mathrm{hem}$ toxicity on endothelium and then discuss our recent data on the therapeutic use of the plasma heme scavenger $\mathrm{Hx}$.

\section{Use of Therapeutic Molecules to Counteract Hb/Heme-Driven Endothelial Dysfunction}

As stated above, the critical roles of endothelial activation, inflammation, and oxidative stress in the pathophysiology of hemolytic diseases have been well established. These studies open the possibility that the administration of antioxidants, inhibitors of endothelial activation, or agents able to restore 


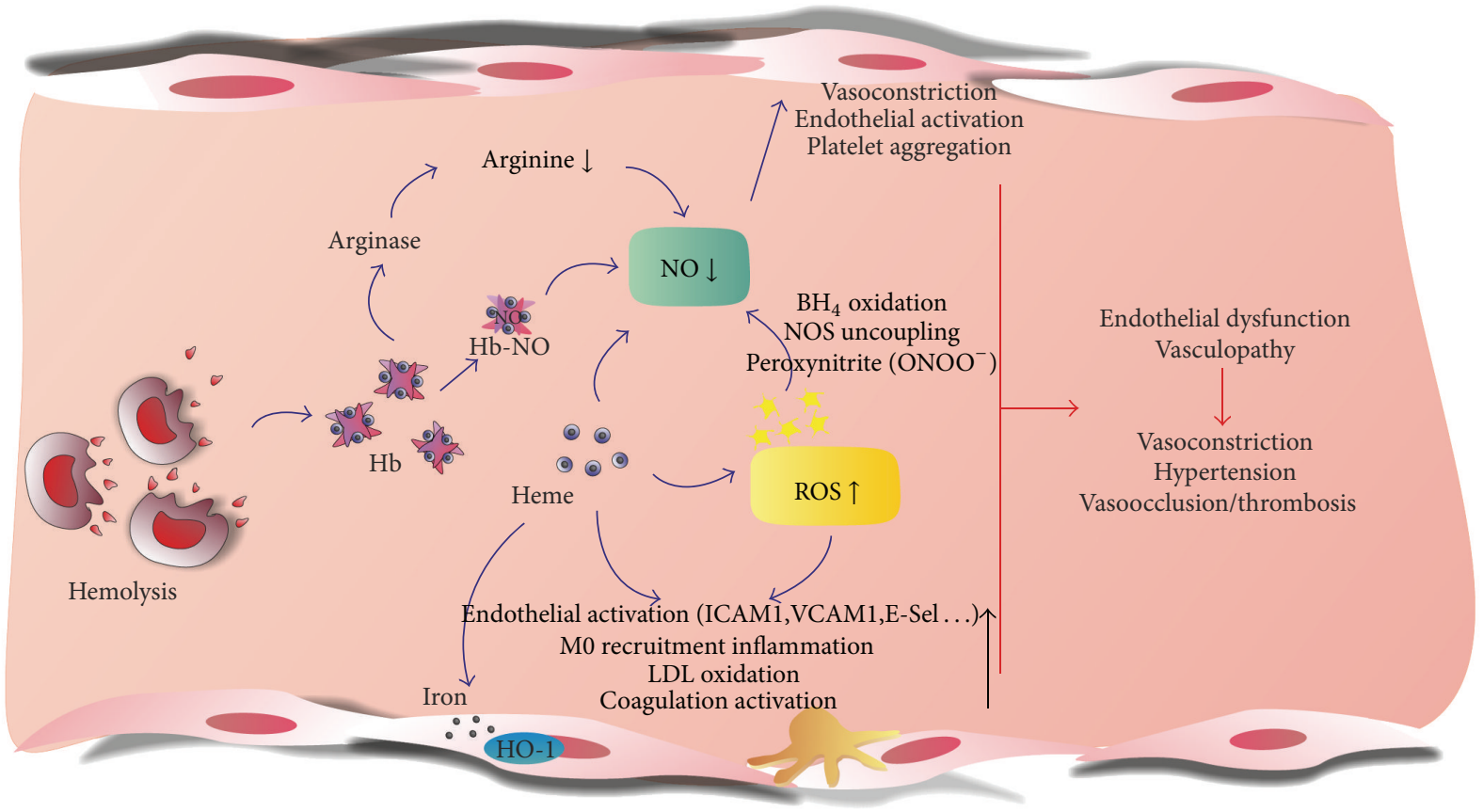

FIGURE 1: Hemolysis-driven endothelial toxicity. Free Hb/heme is responsible for reduced NO availability and ROS generation that contribute to endothelial dysfunction leading to vasoconstriction, hypertension, and vasoocclusion. See text for details.

NO homeostasis, could positively affect cardiovascular function in hemolytic diseases. Moreover, promising therapies are based on systems aimed at enhancing heme degradation and at scavenging $\mathrm{Hb} /$ heme from circulation. Several clinical trials testing the effect of such molecules are ongoing.

3.1. Antioxidants. The antioxidant niacin was found to inhibit vascular inflammation by decreasing endothelial ROS production and subsequent LDL oxidation and inflammatory cytokine production, key events involved in atherogenesis, highlighting vascular anti-inflammatory and potentially antiatherosclerotic properties for this molecule. Treatment with niacin was observed to improve endothelial dysfunction in patients with coronary artery disease and low high-density lipoproteins cholesterol. Niacin is expected to similarly act in SCD, causing an improvement in blood flow, and clinical trials are currently evaluating its therapeutical potential [62]. It has recently been demonstrated that niacin induces HO-1 and that the inhibition of $\mathrm{HO}$ activity attenuates the ability of niacin to inhibit vascular inflammation [63]. These data suggest that the protective effect of niacin on vascular function could be mediated by HO-1 and its products. Nevertheless, it should be taken into account that niacin/nicotinic acid is mildly hemolytic at pharmacologic doses [64], and therefore, it could exacerbate hemolytic damage thus rendering its use not so effective for the treatment of hemolytic patients.

The effect of the supplementation of another molecule, glutamine, in hemolytic patients is under evaluation [65, 66]. Glutamine is expected to improve the erythrocyte glutamine/glutamate ratio, a biomarker of oxidative stress, hemolysis, and $\mathrm{PH}$ in SCD and thalassemia patients and increase arginine bioavailability and subsequently alter sickle red cell endothelial interaction and clinical outcome $[65,67]$. Additionally, oral glutamine is supposed to decrease biomarkers of hemolysis and adhesion molecules and improve the imbalanced arginine-to-ornithine ratio that occurs in hemolytic anemias, leading to improved arginine bioavailability and clinical endpoints of endothelial dysfunction and $\mathrm{PH}$ in patients with SCD and thalassemia $[65,66]$.

The protective effect of erythritol against endothelial dysfunction is also currently being tested. Erythritol, by inducing the expression of SOD2, activates the cell's own antioxidant machinery [68]. This activation or upregulation provides a protective effect to the endothelium and prevents endothelial dysfunction and hemolysis in the streptozotocin diabetic rat [68]. Thus, erythritol could be utilized to treat or prevent hypertension [68].

3.2. Adhesion Molecules Inhibitors. Recent studies suggest a beneficial effect for adhesion molecule inhibitors against hemolysis-induced vasculopathy. Among these molecules, the HDAC inhibitor trichostatin A and its analog suberoylanilide hydroxamic acid were found to markedly reduce endothelial activation and tissue factor expression in transgenic sickle mice, thus preventing vascular stasis [69].

Similarly, the small-molecule cyclic $\alpha \mathrm{V} \beta 3$ and an anti-Pselectin aptamer decrease the adhesion of sickle red blood cells and leukocytes to endothelial cells in mouse model of 
SCD, suggesting a potential use of these molecules as novel therapeutic agents for vasculopathy associated with hemolytic pathologies [70, 71].

3.3. Agents Aimed at Restoring NO Homeostasis. In hemolytic patients, hemolysis-driven endothelial dysfunction is characterized by reduced NO bioavailability and NO resistance, leading to severe vasoconstriction. The effects of cell-free plasma $\mathrm{Hb}$ on $\mathrm{NO}$ consumption have been shown in clinical trials of Hb-based blood substitutes, in which various cellfree $\mathrm{Hb}$ preparations given to humans and animals showed dose-dependent effects on vasoconstriction, $\mathrm{PH}$, and systemic hypertension. Induced intravascular hemolysis in a dog model promoted NO consumption and subsequent vasoconstriction and renal dysfunction [72]. This phenomenon has also been noted in patients with SCD. In these studies, the vasoconstrictive effects of $\mathrm{NO}$ depletion caused by hemolysis could be counteracted by inhaled NO, which reacts directly with the cell-free $\mathrm{Hb}$ in the pulmonary circulation, oxidizing it to metHb, which cannot then scavenge the NO systemically [73].

Additional studies provide evidence for a beneficial effect of inhaled NO and S-nitrosoalbumin on pulmonary injury induced by hypoxia/reoxygenation in a mouse model of SCD [74]. These observations provide new insights into the possible use of NO donors in the treatment of acute lung injury and vasoocclusive crisis in SCD.

A role for arginine supplementation as a novel NObased therapy for SCD has been proposed [75]. Arginine therapy increases NO bioavailability, thus resulting in improved microvascular function and reduced oxidative stress [75]. Consequently, arginine administration decreases pulmonary pressures in patients with SCD and secondary $\mathrm{PH}$ and inhibits endothelin-1-mediated activation of the Gardos channel in transgenic SCD mice, thus limiting erythrocyte dehydration and hemolysis $[54,76,77]$.

Another development in our understanding of $\mathrm{Hb}-\mathrm{NO}$ biology is the appreciation that $\mathrm{Hb}$ possesses a nitrite reductase and anhydrase activity that can convert nitrite to NO and $\mathrm{N}_{2} \mathrm{O}_{3}$, respectively, offsetting the $\mathrm{Hb}$-dependent $\mathrm{NO}$ scavenging by vasodilation. Nitrite reacts with deoxygenated $\mathrm{Hb}$ to form metHb and NO. Consistent with this theory, recent studies have examined the addition of nitrite to $\mathrm{Hb}$ based oxygen carriers and found that low concentrations of nitrite reverse the vasoconstrictive effects. According to this hypothesis, low doses of nitrite could be given before hemodialysis, cardiopulmonary bypass, or transfusion of aged blood to limit the cardiovascular toxicity of NO scavenging [78].

3.4. Enhanced Heme Degradation. In hemolytic patients, heme that accumulated in endothelial cells and in tissues is degraded by $\mathrm{HO}$, mainly by the inducible HO-1 enzyme. HO1 by exerting anti-inflammatory, antiproliferative, antiapoptotic, and antioxidant effects on the vasculature has been shown to protect against atherosclerosis [79]. Moreover, it promotes vascular repair after injury and prevents chronic allograft deterioration in heart transplantation [80, 81]. HO-1 protective effects are mediated by the products of heme catabolism, $\mathrm{CO}$ that is a strong vasodilator, and biliverdin/bilirubin that has antioxidant properties and can regulate the expression of protective genes [2]. In particular, biliverdin/bilirubin themselves scavenges multiple oxidants including superoxide, which would decrease NO bioavailability, induce peroxynitrite formation and contribute to dysregulation of endothelial function $[82,83]$. SCD patients and mice showed an adaptive upregulation of $\mathrm{HO}-1$ in response to hemolysis, and several data demonstrated the cardiovascular protective function of HO-1 [43, 84, 85]. Belcher and coauthors demonstrated that treatment of sickle mice with hemin to increase HO-1 expression inhibits hypoxia/reoxygenationinduced stasis, leukocyte-endothelium interactions, and NFkappaB, VCAM-1, and ICAM-1 expressions. On the other hand, $\mathrm{HO}$ inhibition exacerbates stasis in sickle mice. Furthermore, treatment of sickle mice with the $\mathrm{HO}$ enzymatic product $\mathrm{CO}$ or biliverdin inhibits stasis and NF-kappaB, VCAM-1, and ICAM-1 expressions [43]. Another promising approach is based on the use of viral vectors or transposases to increase HO-1 expression $[84,86]$.

3.5. Plasma $\mathrm{Hb}$ Scavenging. Several studies reported the beneficial effects of $\mathrm{Hp}$ on inhibiting $\mathrm{Hb}$ toxicity [5, 72, 87]. A recent study published by Boretti et al. reports that cell-free plasma $\mathrm{Hb}$ has potent oxidative properties that are associated with hypertensive effects. They also found that increasing the levels of $\mathrm{Hp}$ in the circulation reduced this oxidative stress and limited both the hypertensive effects and the renal insufficiency associated with plasma hemoglobinemia [72].

Other studies reported the therapeutic use of $\mathrm{Hp}$ in animal models of transfusion-associated hemolysis [88]. Finally, $\mathrm{Hp}$ has already been used in several clinical trials in Japan.

The therapeutic use of $\mathrm{Hp}$ has been extensively reviewed by $[5]$.

The different therapeutic approaches discussed in this section are illustrated in Figure 2.

\section{The Plasma Heme Scavenger Hemopexin}

$\mathrm{Hx}$ is a glycoprotein mainly produced by the liver and released into plasma (plasma concentration: $0.5-1 \mathrm{mg} / \mathrm{mL}$ in humans and rodents) where it binds heme with very high affinity. Other than the liver, other sites of Hx synthesis are kidney mesangial cells, neurons, and glial cells of the central nervous system, Schwann cells, and ganglionic and photoreceptor cells of the retina and skeletal muscle $[4,89,90]$. Hx structure is characterized by two domains, resembling two thick disks that lock together at a $90^{\circ}$ angle, joined by a linker peptide. The structure of $\mathrm{Hx}$ is characterized by its conserved clustering of histidine residues present in His-Gly sequences that coordinate heme [91]. The heme ligand is bound between the two domains of $\mathrm{Hx}$ in a pocket formed by the interdomain linker peptide. Heme binding and release result from opening and closing of the heme-binding pocket, through movement of the two domains and/or interdomain linker peptide [92].

Plasma level of $\mathrm{Hx}$ rises during the acute phase response following inflammation and heme overload [93]. Hx synthesis is mainly controlled at the transcriptional level. The human Hx promoter contains a specific cis-acting element, 


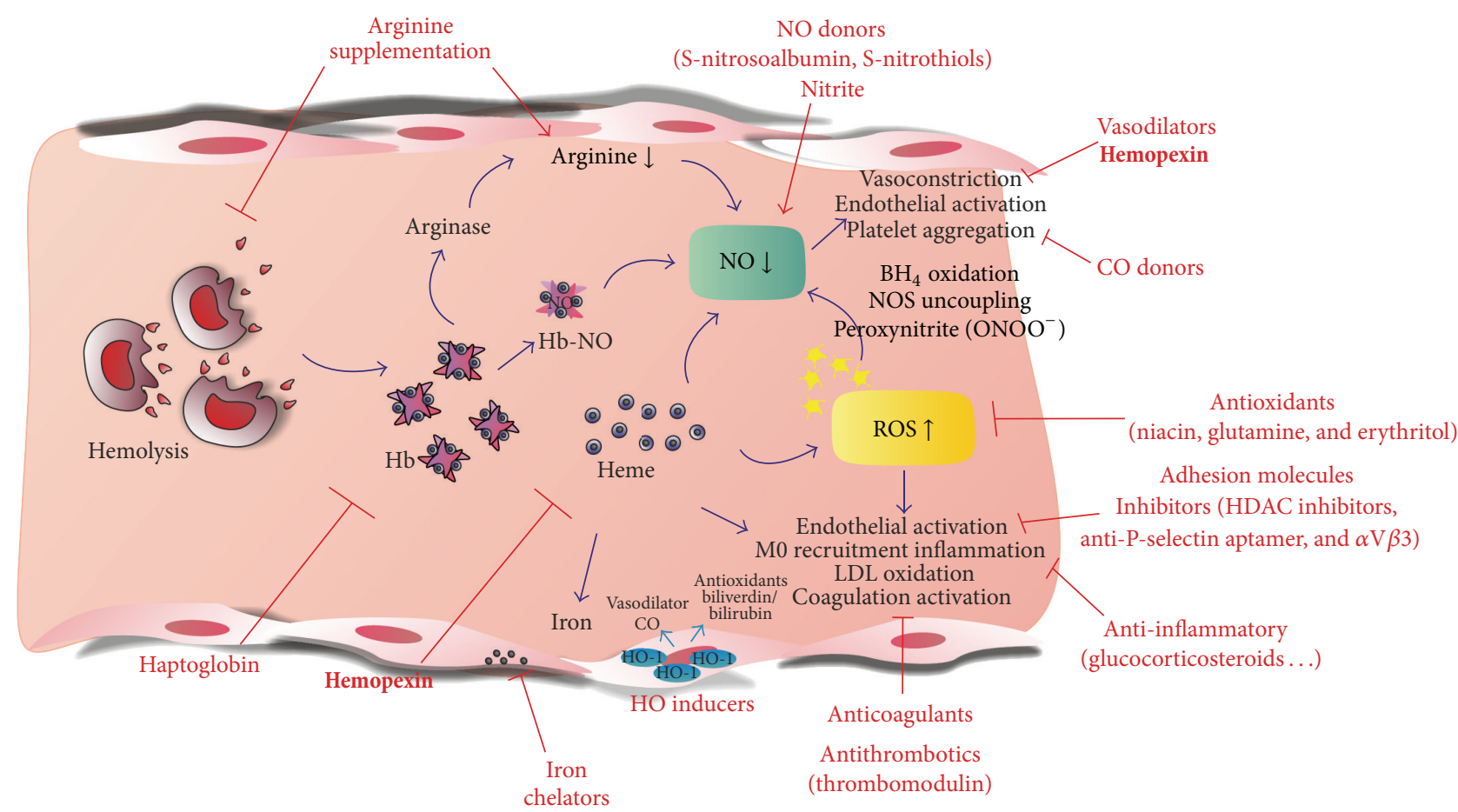

FIgURE 2: Therapeutic approaches aimed at counteracting $\mathrm{Hb} / \mathrm{heme}$ toxicity. It is possible to use agents to restore NO availability, to limit ROS production and inflammation, to induce the protective $\mathrm{HO}-1$ gene, to use $\mathrm{Hb} /$ heme scavengers to block $\mathrm{Hb} /$ heme adverse effects, or to chelate heme-derived prooxidant iron. In principle, combined therapies, by acting at different levels, could be even more effective.

called Hpx A site, which is responsible for interleukin-6mediated induction of $\mathrm{Hx}$ expression [94-96]. On the other hand, it is unknown whether heme directly controls $\mathrm{Hx}$ expression [4].

Studies in $\mathrm{Hx}$-null mice demonstrated a crucial role for this protein in the protection against hemolytic damage. $\mathrm{Hx}-$ null mice are highly sensitive to phenylhydrazine-induced intravascular hemolysis and to heme overload obtained through intravenous injection of heme $[8,97,98]$. The $\mathrm{Hx}$ protective effect is particularly evident on the vasculature, the liver, and the kidney [8]. After heme overload, vessels of $\mathrm{Hx}$-null mice showed an increased induction of adhesion molecules and suffered from oxidative stress. Moreover, NO availability after heme overload was reduced in $\mathrm{Hx}$-null mice, and this was likely due to NOS uncoupling subsequent to heme-promoted ROS generation. Vessel damage was particularly evident in the liver of heme-overloaded Hx knockout mice, where sinusoids appeared congested. Finally, proinflammatory cytokines expression was increased in $\mathrm{Hx}$ null mice after heme overload indicating that $\mathrm{Hx}$ can very efficiently limit heme inflammatory effects $[8,99]$.

Recently, we demonstrated that the Hx protective effect on the endothelium was achieved through the prevention of heme entry into endothelial cells (and/or heme intercalation in endothelial cell membranes) and the promotion of heme detoxification by the liver [99]. Hx very efficiently promotes heme uptake by hepatocytes that detoxify it through $\mathrm{HO}$ and direct excretion in the bile. This in vivo study confirms the previously reported in vitro results showing that treatment of hepatoma cell lines with heme-Hx complexes resulted in the induction of HO-1 and ferritins and thus in an efficient heme catabolism. Moreover, we were able to demonstrate that heme enters into endothelial cells if bound to albumin, but not if bound to $\mathrm{Hx}$, and this was associated with the protection against heme-induced oxidative stress and to the prevention of adhesion molecules induction [99]. Similar results were obtained on macrophages as $\mathrm{Hx}$ also prevents heme entry into this cell type and macrophage activation (Vinchi et al., unpublished data). Interestingly, it has been reported that apo-Hx blocks the induction of IL- 6 and TNF $\alpha$ in LPS-treated macrophages $[100,101]$. This suggests that $\mathrm{Hx}$ can have an anti-inflammatory function independent from its heme scavenger function, likely by acting on TLR4-activated pathways.

\section{Therapeutical Use of Hx to Limit Heme-Driven Endothelial Dysfunction in Hemolytic Disorders}

We recently showed the effects of an $\mathrm{Hx}$-based therapy in mouse models of two hemolytic disorders, SCD and $\beta$ thalassemia. Both these diseases, despite having different etiology and clinical settings, have high rate of intravascular hemolysis as a common feature. Both of these disorders can cause fatigue, jaundice, and episodes of pain ranging from mild to severe. Dysfunction of the liver, lung, kidney, and heart is common, and stroke may occur. Moreover, in severe 
forms of SCD and $\beta$-thalassemia, a transfusion regimen is necessary, and this further exacerbates $\mathrm{Hb} /$ heme toxicity [33].

Our data show that Hx infusion alleviates heme-induced endothelial activation, inflammation, and oxidative injury in mouse models, thus suggesting important implication for a therapeutic use of $\mathrm{Hx}$ in the treatment of hemolytic diseases (Figure 2).

Hx treatment resulted in a marked improvement of the health status of anemic mice and preservation of their organ functionality. In particular, we demonstrated that $\mathrm{Hx}$ administration, by scavenging free heme, alleviates heme-induced ROS formation and tissue oxidative injury and limits the induction of adhesion molecules in SCD and $\beta$-thalassemia mice, thus indicating that $\mathrm{Hx}$ may confer protection against heme-driven oxidative stress as well as endothelial activation and inflammation [99]. Moreover, we showed that $\mathrm{Hx}$ therapy promotes NO production by reducing heme-induced oxidative consumption of NOS cofactors and NOS enzyme uncoupling. Increased bioavailability of NO suggests that $\mathrm{Hx}$ is able to positively affect vascular homeostasis, counteracting endothelial dysfunction associated with hemolytic pathologies [99].

Our recent data also indicate a strong antihypertensive role for $\mathrm{Hx}$ in hemolytic pathologies. Hx therapy strongly reduces blood pressure in hemolytic animals, counteracting heme-induced vasoconstriction. This is further supported by a marked decrease in cardiac output and aortic valve peak pressure observed in SCD mice following Hx therapy [99].

Additionally, $\mathrm{Hx}$ administration reduces proinflammatory cytokine production in hemolytic animals, supporting a strong anti-inflammatory role for this molecule [99]. Compared to other anti-inflammatory agents such as glucocorticosteroids that have a limited use in clinics because of their side effects and immunosuppressive impact, $\mathrm{Hx}$, by acting as a physiologic heme chelator, is expected to be well tolerated. We did not observe deleterious effects of the Hx therapy on renal function in mice despite the fact that previous papers had described a protease activity of serum $\mathrm{Hx}$ responsible for proteinuria and glomerular alterations characteristic for minimal change nephrotic syndrome in the rat $[102,103]$. This might be due to the different preparations of Hx used or, more likely, to the different pathologic models analysed. Our data support the conclusion that $\mathrm{Hx}$ is the most important heme scavenger under conditions of enhanced hemolysis as those experienced by SCD and thalassemic mice when plasma hemoglobin levels exceed haptoglobin binding capacity.

$\mathrm{Hx}$ exerts its protective effect mainly by enhancing $\mathrm{HO}$ expression and activity in the liver and by limiting HO-1 induction in vascular endothelium and likely in other extrahepatic tissues [99].

In SCD and thalassemic patients, excess iron deposition in the liver, further worsened by transfusion, may cause fibrosis/cirrhosis and hepatocellular carcinoma. Nevertheless, the beneficial effects due to $\mathrm{Hx}$ treatment observed in anemic mice support the idea that the organism can tolerate a greater iron burden in the liver that is a tissue predisposed to iron storage, while it is preferable to alleviate iron loading in tissues, such as the heart and kidney that are not usually predisposed to iron accumulation [104]. In addition, we demonstrated that Hx treatment also promotes heme excretion in the bile, thus providing a way for iron to directly leave the body [99]. This represents a mechanism on which to act in the future in order to enhance the liver heme detoxifying potential.

On the other hand, by redirecting heme to the liver, $\mathrm{Hx}$ limits heme uptake and prevents HO-1 induction as well as iron loading and activation of endothelial cells, thus reducing ROS production, inflammation, and, eventually, cell death. These results are in agreement with data showing that HO1 transgene expression in the liver of sickle mice resulted in a decrease in markers of vascular inflammation and inhibition of vasoocclusion [84]. Indeed, an important outcome of $\mathrm{Hx}$ therapy is the prevention of iron accumulation in the vascular endothelium and in the heart. This has clinical relevance since hemolysis-driven iron overload, exacerbated by blood transfusions, strongly contributes to heart failure, one of the most common causes of death in thalassemia patients. Our results suggest that $\mathrm{Hx}$ administration could be beneficial in transfused patients to alleviate the myocardial iron burden.

These data provide the rationale for the use of purified or recombinant $\mathrm{Hx}$ and/or for the design of Hx-based drugs, with high affinity for heme and rapidly cleared by the liver, which might be used pharmacologically as heme chelators to prevent heme-mediated tissue damage in patients suffering from hemolytic diseases.

\section{Conclusions}

Free $\mathrm{Hb} /$ heme resulting from hemolysis is responsible for reduced NO availability, oxidative stress, and inflammation, all contributing to vascular dysfunction. Therapeutic approaches are aimed at enhancing heme degradation, at counteracting heme prooxidant activity, at limiting endothelial activation, and at preserving NO homeostasis. Promising novel therapies are based on the use of plasma $\mathrm{Hb}$ and heme scavengers to prevent $\mathrm{Hb} / \mathrm{heme}$ toxicity. In particular, the use of purified $\mathrm{Hx}$ in mouse models of SCD and $\beta$-thalassemia has provided the proof of principle of such approach. Future studies are needed to translate these results into clinical practice. Considering that the different approaches described in this review target different levels of the cascade of events starting with $\mathrm{Hb} /$ heme overload and ending with vascular dysfunction, it is time to speculate on the effectiveness of combined therapies. For instance, we expect that promoting $\mathrm{Hb}$ and heme scavenging with $\mathrm{Hp}$ and $\mathrm{Hx}$, respectively, and simultaneously enhancing HO-1 expression may almost completely avoid heme accumulation and consequently its toxic effects. Similarly, the association of antioxidants and/or drugs aimed at restoring NO may improve the effectiveness of $\mathrm{Hb} /$ heme scavenging.

\section{Funding}

This work was supported by Telethon Grant GGP12082. 


\section{References}

[1] G. Dhaliwal, P. A. Cornett, and L. M. Tierney, "Hemolytic anemia," American Family Physician, vol. 69, no. 11, pp. 25992606, 2004.

[2] R. Gozzelino, V. Jeney, and M. P. Soares, "Mechanisms of cell protection by heme oxygenase-1," Annual Review of Pharmacology and Toxicology, vol. 50, pp. 323-354, 2010.

[3] C. Meyer, C. Heiss, C. Drexhage et al., "Hemodialysis-induced release of hemoglobin limits nitric oxide bioavailability and impairs vascular function," Journal of the American College of Cardiology, vol. 55, no. 5, pp. 454-459, 2010.

[4] E. Tolosano, S. Fagoonee, N. Morello, F. Vinchi, and V. Fiorito, "Heme scavenging and the other facets of hemopexin," Antioxidants \& Redox Signaling, vol. 12, no. 2, pp. 305-320, 2010.

[5] D. J. Schaer, P. W. Buehler, A. I. Alayash, J. D. Belcher, and G. M. Vercellotti, "Hemolysis and free hemoglobin revisited: exploring hemoglobin and hemin scavengers as a novel class of therapeutic proteins," Blood, vol. 121, pp. 1276-1284, 2013.

[6] W. T. Morgan, "The binding and transport of heme by hemopexin," Annals of Clinical Research, vol. 8, supplement 17, pp. 223-232, 1976.

[7] W. T. Morgan, H. H. Liem, R. P. Sutor, and U. Muller Eberhard, "Transfer of heme from heme albumin to hemopexin," Biochimica et Biophysica Acta, vol. 444, no. 2, pp. 435-445, 1976.

[8] F. Vinchi, S. Gastaldi, L. Silengo, F. Altruda, and E. Tolosano, "Hemopexin prevents endothelial damage and liver congestion in a mouse model of heme overload," American Journal of Pathology, vol. 173, no. 1, pp. 289-299, 2008.

[9] E. Seixas, R. Gozzelino, A. Chora et al., "Heme oxygenase-1 affords protection against noncerebral forms of severe malaria," Proceedings of the National Academy of Sciences of the United States of America, vol. 106, no. 37, pp. 15837-15842, 2009.

[10] T. Jansen and A. Daiber, "Direct antioxidant properties of bilirubin and biliverdin. Is there a role for biliverdin reductase?" Frontiers in Pharmacology, vol. 3, article 30, 2012.

[11] B. Wegiel and L. E. Otterbein, "Go green: the anti-inflammatory effects of biliverdin reductase," Frontiers in Pharmacology, vol. 3, article 47, 2012.

[12] A. C. Bulmer, J. S. Coombes, J. T. Blanchfield, I. Toth, R. G. Fassett, and S. M. Taylor, "Bile pigment pharmacokinetics and absorption in the rat: therapeutic potential for enteral administration," British Journal of Pharmacology, vol. 164, pp. 1857-1870, 2011.

[13] W. K. Mccoubrey, T. J. Huang, and M. D. Maines, "Isolation and characterization of a cDNA from the rat brain that encodes hemoprotein heme oxygenase-3," European Journal of Biochemistry, vol. 247, no. 2, pp. 725-732, 1997.

[14] S. Hayashi, Y. Omata, H. Sakamoto et al., "Characterization of rat heme oxygenase-3 gene. Implication of processed pseudogenes derived from heme oxygenase-2 gene," Gene, vol. 336, no. 2, pp. 241-250, 2004.

[15] H. Parfenova and C. W. Leffler, "Cerebroprotective functions of HO-2," Current Pharmaceutical Design, vol. 14, no. 5, pp. 443$453,2008$.

[16] S. Shibahara, F. Han, B. Li, and K. Takeda, "Hypoxia and heme oxygenases: oxygen sensing and regulation of expression," Antioxidants \& Redox Signaling, vol. 9, no. 12, pp. 2209-2225, 2007.

[17] P. Arosio and S. Levi, "Ferritin, iron homeostasis, and oxidative damage," Free Radical Biology and Medicine, vol. 33, no. 4, pp. 457-463, 2002.
[18] L. L. Hsu, H. C. Champion, S. A. Campbell-Lee et al., "Hemolysis in sickle cell mice causes pulmonary hypertension due to global impairment in nitric oxide bioavailability," Blood, vol. 109, no. 7, pp. 3088-3098, 2007.

[19] M. T. Lee, E. B. Rosenzweig, and M. S. Cairo, "Pulmonary hypertension in sickle cell disease," Clinical Advances in Hematology and Oncology, vol. 5, no. 8, pp. 585-653, 2007.

[20] A. Hill, R. J. Sapsford, A. Scally et al., "Under-recognized complications in patients with paroxysmal nocturnal haemoglobinuria: raised pulmonary pressure and reduced right ventricular function," British Journal of Haematology, vol. 158, no. 3, pp. 409-414, 2012.

[21] S. E. Crary, C. Ramaciotti, and G. R. Buchanan, "Prevalence of pulmonary hypertension in hereditary spherocytosis," American Journal of Hematology, vol. 86, no. 12, pp. E73-E76, 2011.

[22] K. Ishigaki, Y. Takizawa, J. Maruyama, and K. Setoguchi, "Pulmonary thrombotic microangiopathic hemolytic anemia treated successfully with anticoagulant monotherapy," Internal Medicine, vol. 49, no. 12, pp. 1217-1220, 2010.

[23] C. Bachmeyer, A. Khalil, K. Kerrou, R. Girot, and V. Gounant, "Idiopathic pulmonary arterial hypertension in a patient with pyruvate kinase deficiency and paravertebral extramedullary hematopoiesis," Annals of Hematology, vol. 88, no. 6, pp. 603$605,2009$.

[24] J. J. Janka, O. A. Koita, B. Traoré et al., "Increased pulmonary pressures and myocardial wall stress in children with severe malaria," Journal of Infectious Diseases, vol. 202, no. 5, pp. 791800, 2010.

[25] A. Taksande, S. Prabhu, and S. Venkatesh, "Cardiovascular aspect of beta-thalassaemia," Cardiovascular \& Hematological Agents in Medicinal Chemistry, vol. 10, no. 1, pp. 25-30, 2012.

[26] A. P. Vlahos, F. P. Koutsouka, N. D. Papamichael et al., "Determinants of pulmonary hypertension in patients with Beta-thalassemia major and normal ventricular function," Acta Haematologica, vol. 128, pp. 124-129, 2012.

[27] F. J. Smiers, L. Krishnamurti, and G. Lucarelli, "Hematopoietic stem cell transplantation for hemoglobinopathies: current practice and emerging trends," Pediatric Clinics of North America, vol. 57, no. 1, pp. 181-205, 2010.

[28] R. S. Olney, "Preventing morbidity and mortality from sickle cell disease: a public health perspective," American Journal of Preventive Medicine, vol. 16, no. 2, pp. 116-121, 1999.

[29] J. Balla, G. M. Vercellotti, V. Jeney et al., "Heme, heme oxygenase and ferritin in vascular endothelial cell injury," Molecular Nutrition and Food Research, vol. 49, no. 11, pp. 1030-1043, 2005.

[30] V. Jeney, J. Balla, A. Yachie et al., "Pro-oxidant and cytotoxic effects of circulating heme," Blood, vol. 100, no. 3, pp. 879-887, 2002.

[31] R. T. Figueiredo, P. L. Fernandez, D. S. Mourao-Sa et al., "Characterization of heme as activator of toll-like receptor 4," Journal of Biological Chemistry, vol. 282, no. 28, pp. 2022120229, 2007.

[32] S. Kumar and U. Bandyopadhyay, "Free heme toxicity and its detoxification systems in human," Toxicology Letters, vol. 157, no. 3, pp. 175-188, 2005.

[33] C. R. Morris, "Mechanisms of vasculopathy in sickle cell disease and thalassemia," Hematology, pp. 177-185, 2008.

[34] I. Akinsheye and E. S. Klings, "Sickle cell anemia and vascular dysfunction: the nitric oxide connection," Journal of Cellular Physiology, vol. 224, no. 3, pp. 620-625, 2010. 
[35] M. Aslan and B. A. Freeman, "Redox-dependent impairment of vascular function in sickle cell disease," Free Radical Biology and Medicine, vol. 43, no. 11, pp. 1469-1483, 2007.

[36] L. de Franceschi, M. D. Cappellini, and O. Olivieri, "Thrombosis and sickle cell disease," Seminars in Thrombosis and Hemostasis, vol. 37, no. 3, pp. 226-236, 2011.

[37] G. Hahalis, D. T. Kremastinos, G. Terzis et al., "Global vasomotor dysfunction and accelerated vascular aging in $\beta$-thalassemia major," Atherosclerosis, vol. 198, no. 2, pp. 448-457, 2008.

[38] J. S. Pober, W. Min, and J. R. Bradley, "Mechanisms of endothelial dysfunction, injury, and death," Annual Review of Pathology, vol. 4, pp. 71-95, 2009.

[39] W. H. Park, "The effects of exogenous $\mathrm{H}_{2} \mathrm{O}_{2}$ on cell death, reactive oxygen species and glutathione levels in calf pulmonary artery and human umbilical vein endothelial cells," International Journal of Molecular Medicine, vol. 31, pp. 471-476, 2013.

[40] N. T. Jenkins, J. Padilla, L. J. Boyle, D. P. Credeur, M. H. Laughlin, and P. J. Fadel, "Disturbed blood flow acutely induces activation and apoptosis of the human vascular endothelium," Hypertension, vol. 61, pp. 615-621, 2013.

[41] T. Hirase and K. Node, "Endothelial dysfunction as a cellular mechanism for vascular failure," American Journal of Physiology, vol. 302, pp. H499-H505, 2012.

[42] J. D. Belcher, H. Mahaseth, T. E. Welch et al., "Critical role of endothelial cell activation in hypoxia-induced vasoocclusion in transgenic sickle mice," American Journal of Physiology, vol. 288, no. 6, pp. H2715-H2725, 2005.

[43] J. D. Belcher, H. Mahaseth, T. E. Welch, L. E. Otterbein, R. P. Hebbel, and G. M. Vercellotti, "Heme oxygenase-1 is a modulator of inflammation and vaso-occlusion in transgenic sickle mice," Journal of Clinical Investigation, vol. 116, no. 3, pp. 808-816, 2006.

[44] T. Hovav, A. Goldfarb, G. Artmann, S. Yedgar, and G. Barshtein, "Enhanced adherence of $\beta$-thalassaemic erythrocytes to endothelial cells," British Journal of Haematology, vol. 106, no. 1, pp. 178-181, 1999.

[45] D. M. Tabima, S. Frizzell, and M. T. Gladwin, "Reactive oxygen and nitrogen species in pulmonary hypertension," Free Radical Biology and Medicine, vol. 52, no. 9, pp. 1970-1986, 2012.

[46] E. Stoyanova, M. Trudel, H. Felfly, W. Lemsaddek, D. Garcia, and G. Cloutier, "Vascular endothelial dysfunction in $\beta$ thalassemia occurs despite increased eNOS expression and preserved vascular smooth muscle cell reactivity to NO," PLoS One, vol. 7, Article ID e38089, 2012.

[47] G. Yetik-Anacak and J. D. Catravas, "Nitric oxide and the endothelium: history and impact on cardiovascular disease," Vascular Pharmacology, vol. 45, no. 5, pp. 268-276, 2006.

[48] H. Qian, V. Neplioueva, G. A. Shetty, K. M. Channon, and S. E. George, "Nitric oxide synthase gene therapy rapidly reduces adhesion molecule expression and inflammatory cell infiltration in carotid arteries of cholesterol-fed rabbits," Circulation, vol. 99, no. 23, pp. 2979-2982, 1999.

[49] P. Ferroni, N. Vazzana, S. Riondino, C. Cuccurullo, F. Guadagni, and G. Davì, "Platelet function in health and disease: from molecular mechanisms, redox considerations to novel therapeutic opportunities," Antioxid Redox Signal, vol. 17, no. 10, pp. 1447-1485, 2012.

[50] I. Sudano, S. Roas, and G. Noll, "Vascular abnormalities in essential hypertension," Current Pharmaceutical Design, vol. 17, no. 28, pp. 3039-3044, 2011.
[51] K. C. Wood, L. L. Hsu, and M. T. Gladwin, "Sickle cell disease vasculopathy: a state of nitric oxide resistance," Free Radical Biology and Medicine, vol. 44, no. 8, pp. 1506-1528, 2008.

[52] D. K. Kaul and R. P. Hebbel, "Hypoxia/reoxygenation causes inflammatory response in transgenic sickle mice but not in normal mice," The Journal of Clinical Investigation, vol. 106, no. 3, pp. 411-420, 2000.

[53] J. H. Maley, G. F. Lasker, and P. J. Kadowitz, "Nitric oxide and disorders of the erythrocyte: emerging roles and therapeutic targets," Cardiovascular and Hematological Disorders Drug Targets, vol. 10, no. 4, pp. 284-291, 2010.

[54] M. R. Abboud and K. M. Musallam, "Sickle cell disease at the dawn of the molecular era," Hemoglobin, vol. 33, supplement 1 , pp. S93-S106, 2009.

[55] G. J. Kato and J. G. Taylor, "Pleiotropic effects of intravascular haemolysis on vascular homeostasis," British Journal of Haematology, vol. 148, no. 5, pp. 690-701, 2010.

[56] P. Mustajoki and Y. Nordmann, "Early administration of heme arginate for acute porphyric attacks," Archives of Internal Medicine, vol. 153, no. 17, pp. 2004-2008, 1993.

[57] T. T. T. Timonen and H. Kauma, "Therapeutic effect of heme arginate in myelodysplastic syndromes," European Journal of Haematology, vol. 49, no. 5, pp. 234-238, 1992.

[58] J. W. Park, B. Piknova, P. L. Huang, C. T. Noguchi, and A. N. Schechter, "Effect of blood nitrite and nitrate levels on murine platelet function," PLoS One, vol. 8, Article ID e55699, 2013.

[59] J. C. Wanstall, K. L. Homer, and S. A. Doggrell, "Evidence for, and importance of, cGMP-independent mechanisms with NO and NO donors on blood vessels and platelets," Current Vascular Pharmacology, vol. 3, no. 1, pp. 41-53, 2005.

[60] J. D. Belcher, P. H. Marker, J. P. Weber, R. P. Hebbel, and G. M. Vercellotti, "Activated monocytes in sickle cell disease: potential role in the activation of vascular endothelium and vaso-occlusion," Blood, vol. 96, no. 7, pp. 2451-2459, 2000.

[61] U. R. Osarogiagbon, S. Choong, J. D. Belcher, G. M. Vercellotti, M. S. Paller, and R. P. Hebbel, "Reperfusion injury pathophysiology in sickle transgenic mice," Blood, vol. 96, no. 1, pp. 314-320, 2000.

[62] D. K. Kaul, X. D. Liu, X. Zhang, L. Ma, C. J. C. Hsia, and R. L. Nagel, "Inhibition of sickle red cell adhesion and vasoocclusion in the microcirculation by antioxidants," American Journal of Physiology, vol. 291, no. 1, pp. H167-H175, 2006.

[63] B. J. Wu, K. Chen, P. J. Barter, and K. A. Rye, "Niacin inhibits vascular inflammation via the induction of heme oxygenase-1," Circulation, vol. 125, pp. 150-158, 2012.

[64] S. Gentile and F. Gentile, "Hypersideremic and hyperbilirubinemic effect of nicotinic acid in patients with Gilbert's syndrome," Hepato-Gastroenterology, vol. 34, no. 4, pp. 152-154, 1987.

[65] Y. Niihara, C. R. Zerez, D. S. Akiyama, and K. R. Tanaka, "Oral L-glutamine therapy for sickle cell anemia: I. Subjective clinical improvement and favorable change in red cell NAD redox potential," American Journal of Hematology, vol. 58, pp. 117-121, 1998.

[66] Y. Niihara, N. M. Matsui, Y. M. Shen et al., "L-glutamine therapy reduces endothelial adhesion of sickle red blood cells to human umbilical vein endothelial cells," BMC Blood Disorders, vol. 5, article 4, 2005.

[67] C. R. Morris, J. H. Suh, W. Hagar et al., "Erythrocyte glutamine depletion, altered redox environment, and pulmonary hypertension in sickle cell disease," Blood, vol. 111, no. 1, pp. 402-410, 2008. 
[68] G. J. M. den Hartog, A. W. Boots, A. Adam-Perrot et al., "Erythritol is a sweet antioxidant," Nutrition, vol. 26, no. 4, pp. 449458, 2010.

[69] R. P. Hebbel, G. M. Vercellotti, B. S. Pace et al., "The HDAC inhibitors trichostatin A and suberoylanilide hydroxamic acid exhibit multiple modalities of benefit for the vascular pathobiology of sickle transgenic mice," Blood, vol. 115, no. 12, pp. 24832490, 2010.

[70] E. M. Finnegan, G. A. Barabino, X. D. Liu, H. Y. Chang, A. Jonczyk, and D. K. Kaul, "Small-molecule cyclic $\alpha \mathrm{V} \beta 3$ antagonists inhibit sickle red cell adhesion to vascular endothelium and vasoocclusion," American Journal of Physiology, vol. 293, no. 2, pp. H1038-H1045, 2007.

[71] D. R. Gutsaeva, J. B. Parkerson, S. D. Yerigenahally et al., "Inhibition of cell adhesion by anti-P-selectin aptamer: a new potential therapeutic agent for sickle cell disease," Blood, vol. 117, no. 2, pp. 727-735, 2011.

[72] F. S. Boretti, P. W. Buehler, F. D’Agnillo et al., "Sequestration of extracellular hemoglobin within a haptoglobin complex decreases its hypertensive and oxidative effects in dogs and guinea pigs," Journal of Clinical Investigation, vol. 119, no. 8, pp. 2271-2280, 2009.

[73] L. de Franceschi, A. Baron, A. Scarpa et al., "Inhaled nitric oxide protects transgenic SAD mice from sickle cell disease-specific lung injury induced by hypoxia/reoxygenation," Blood, vol. 102, no. 3, pp. 1087-1096, 2003.

[74] L. de Franceschi, G. Malpeli, A. Scarpa et al., "Protective effects of S-nitrosoalbumin on lung injury induced by hypoxiareoxygenation in mouse model of sickle cell disease," American Journal of Physiology, vol. 291, no. 3, pp. L457-L465, 2006.

[75] D. K. Kaul, X. Zhang, T. Dasgupta, and M. E. Fabry, "Arginine therapy of transgenic-knockout sickle mice improves microvascular function by reducing non-nitric oxide vasodilators, hemolysis, and oxidative stress," American Journal of Physiology, vol. 295, no. 1, pp. H39-H47, 2008.

[76] C. R. Morris, "New strategies for the treatment of pulmonary hypertension in sickle cell disease: the rationale for arginine therapy," Treatments in Respiratory Medicine, vol. 5, no. 1, pp. 31-45, 2006.

[77] R. L. Benza, "Pulmonary hypertension associated with sickle cell disease: pathophysiology and rationale for treatment," Lung, vol. 186, no. 4, pp. 247-254, 2008.

[78] T. A. Silverman and R. B. Weiskopf, "Hemoglobin-based oxygen carriers: current status and future directions," Transfusion, vol. 49, no. 11, pp. 2495-2515, 2009.

[79] T. Li, H. Tian, Y. Zhao et al., "Heme oxygenase-1 inhibits progression and destabilization of vulnerable plaques in a rabbit model of atherosclerosis," European Journal of Pharmacology, vol. 672, no. 1-3, pp. 143-152, 2011.

[80] T. Y. Tsui, X. Wu, C. K. Lau et al., "Prevention of chronic deterioration of heart allograft by recombinant adeno-associated virusmediated heme oxygenase-1 gene transfer," Circulation, vol. 107, no. 20, pp. 2623-2629, 2003.

[81] J. A. Araujo, L. Meng, A. D. Tward et al., "Systemic rather than local heme oxygenase-1 overexpression improves cardiac allograft outcomes in a new transgenic mouse," Journal of Immunology, vol. 171, no. 3, pp. 1572-1580, 2003.

[82] T. Jansen, M. Hortmann, M. Oelze et al., "Conversion of biliverdin to bilirubin by biliverdin reductase contributes to endothelial cell protection by heme oxygenase-1-evidence for direct and indirect antioxidant actions of bilirubin," Journal of
Molecular and Cellular Cardiology, vol. 49, no. 2, pp. 186-195, 2010.

[83] K. A. Nath, L. V. d'Uscio, J. P. Juncos et al., "An analysis of the DOCA-salt model of hypertension in HO-1-/- mice and the Gunn rat," American Journal of Physiology, vol. 293, no. 1, pp. H333-H342, 2007.

[84] J. D. Belcher, J. V. Vineyard, C. M. Bruzzone et al., "Heme oxygenase-1 gene delivery by Sleeping Beauty inhibits vascular stasis in a murine model of sickle cell disease," Journal of Molecular Medicine, vol. 88, no. 7, pp. 665-675, 2010.

[85] J. D. Belcher, J. D. Beckman, G. Balla, J. Balla, and G. Vercellotti, "Heme degradation and vascular injury," Antioxidants \& Redox Signaling, vol. 12, no. 2, pp. 233-248, 2010.

[86] Q. Li, Y. Guo, Q. Ou et al., "Gene transfer as a strategy to achieve permanent cardioprotection II: rAAV-mediated gene therapy with heme oxygenase-1 limits infarct size 1 year later without adverse functional consequences," Basic Research in Cardiology, vol. 106, no. 6, pp. 1367-1377, 2011.

[87] M. Lipiski, J. W. Deuel, J. H. Baek, W. R. Engelsberger, P. W. Buehler, and D. J. Schaer, "Human Hp1-1 and Hp2-2 phenotypespecific haptoglobin therapeutics are both effective in vitro and in guinea pigs to attenuate hemoglobin toxicity," Antioxidants \& Redox Signaling, 2013.

[88] J. H. Baek, F. D’Agnillo, F. Vallelian et al., "Hemoglobin-driven pathophysiology is an in vivo consequence of the red blood cell storage lesion that can be attenuated in guinea pigs by haptoglobin therapy," The Journal of Clinical Investigation, vol. 122, no. 4, pp. 1444-1458, 2012.

[89] C. M. Morris, J. M. Candy, J. A. Edwardson, C. A. Bloxham, and A. Smith, "Evidence for the localization of haemopexin immunoreactivity in neurones in the human brain," Neuroscience Letters, vol. 149, no. 2, pp. 141-144, 1993.

[90] N. Morello, E. Tonoli, F. Logrand et al., "Haemopexin affects iron distribution and ferritin expression in mouse brain," Journal of Cellular and Molecular Medicine, vol. 13, no. 10, pp. 4192-4204, 2009.

[91] N. Takahashi, Y. Takahashi, and F. W. Putnam, "Structure of human hemopexin: O-glycosyl and N-glycosyl sites and unusual clustering of tryptophan residues," Proceedings of the National Academy of Sciences of the United States of America, vol. 81, no. 7, pp. 2021-2025, 1984.

[92] M. Paoli, B. F. Anderson, H. M. Baker, W. T. Morgan, A. Smith, and E. N. Baker, "Crystal structure of hemopexin reveals a novel high-affinity heme site formed between two $\beta$-propeller domains," Nature Structural Biology, vol. 6, no. 10, pp. 926-931, 1999.

[93] E. Tolosano and F. Altruda, "Hemopexin: structure, function, and regulation," DNA and Cell Biology, vol. 21, no. 4, pp. 297306, 2002.

[94] H. Satoh, Y. Nagae, S. Immenschuh, T. Satoh, and U. MullerEberhard, "Identification of a liver preference enhancer element of the rat hemopexin gene and its interaction with nuclear factors," Journal of Biological Chemistry, vol. 269, no. 9, pp. 6851$6858,1994$.

[95] S. Immenschuh, Y. Nagae, H. Satoh, H. Baumann, and U. Muller-Eberhard, "The rat and human hemopexin genes contain an identical interleukin-6 response element that is not a target of CAAT enhancer-binding protein isoforms," Journal of Biological Chemistry, vol. 269, no. 17, pp. 12654-12661, 1994.

[96] S. Immenschuh, D. X. Song, H. Satoh, and U. Muller-Eberhard, "The type II hemopexin interleukin-6 response element 
predominates the transcriptional regulation of the hemopexin acute phase responsiveness," Biochemical and Biophysical Research Communications, vol. 207, no. 1, pp. 202-208, 1995.

[97] E. Tolosano, E. Hirsch, E. Patrucco et al., "Defective recovery and severe renal damage after acute hemolysis in hemopexindeficient mice," Blood, vol. 94, no. 11, pp. 3906-3914, 1999.

[98] E. Tolosano, S. Fagoonee, E. Hirsch et al., "Enhanced splenomegaly and severe liver inflammation in haptoglobin/hemopexin double-null mice after acute hemolysis," Blood, vol. 100, no. 12, pp. 4201-4208, 2002.

[99] F. Vinchi, L. de Franceschi, A. Ghigo et al., "Hemopexin therapy improves cardiovascular function by preventing heme-induced endothelial toxicity in mouse models of hemolytic diseases," Circulation, vol. 127, no. 12, pp. 1317-1329, 2013.

[100] X. Liang, T. Lin, G. Sun, L. Beasley-Topliffe, J. M. Cavaillon, and H. S. Warren, "Hemopexin down-regulates LPS-induced proinflammatory cytokines from macrophages," Journal of Leukocyte Biology, vol. 86, no. 2, pp. 229-235, 2009.

[101] T. Lin, Y. H. Kwak, F. Sammy et al., "Synergistic inflammation is induced by blood degradation products with microbial Tolllike receptor agonists and is blocked by hemopexin," Journal of Infectious Diseases, vol. 202, no. 4, pp. 624-632, 2010.

[102] P. K. Cheung, P. A. Klok, J. F. W. Baller, and W. W. Bakker, "Induction of experimental proteinuria in vivo following infusion of human plasma hemopexin," Kidney International, vol. 57, no. 4, pp. 1512-1520, 2000.

[103] W. W. Bakker, T. Borghuis, M. C. Harmsen et al., "Protease activity of plasma hemopexin," Kidney International, vol. 68, no. 2, pp. 603-610, 2005.

[104] M. W. Hentze, M. U. Muckenthaler, B. Galy, and C. Camaschella, "Two to tango: regulation of mammalian iron metabolism," Cell, vol. 142, no. 1, pp. 24-38, 2010. 


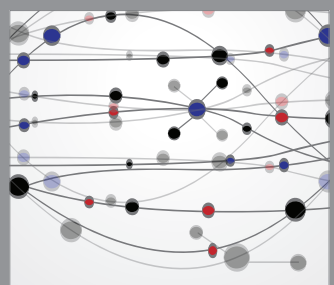

The Scientific World Journal
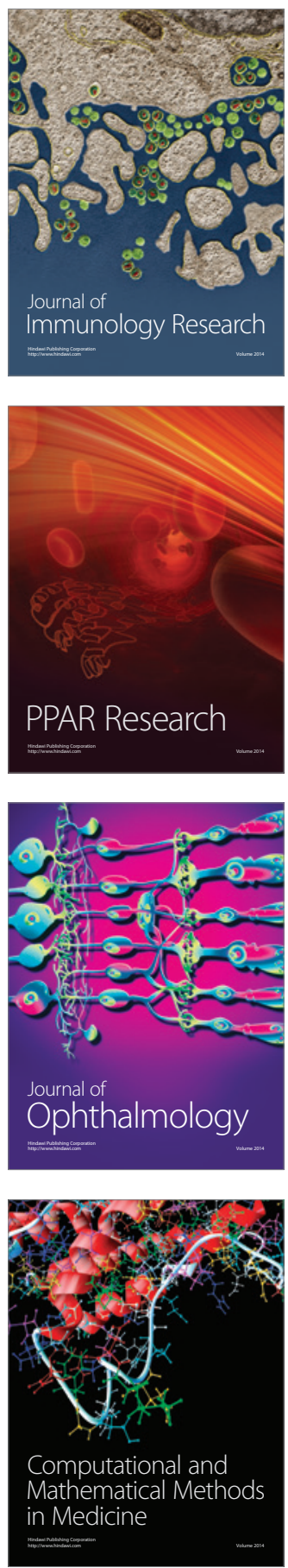

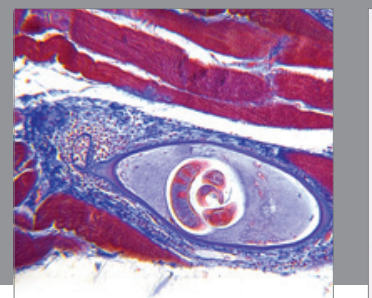

Gastroenterology

Research and Practice
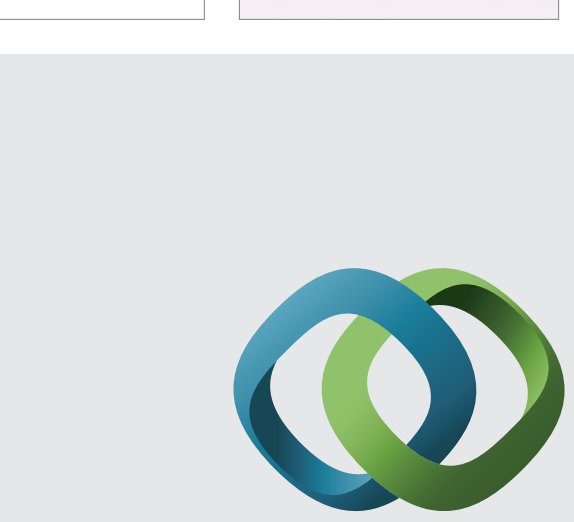

\section{Hindawi}

Submit your manuscripts at

http://www.hindawi.com
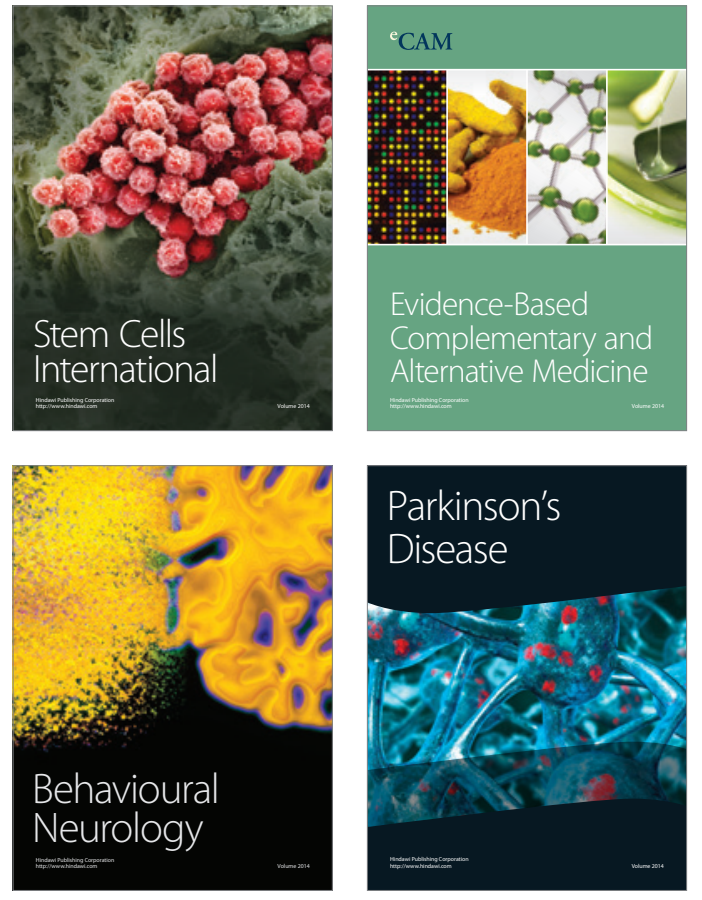
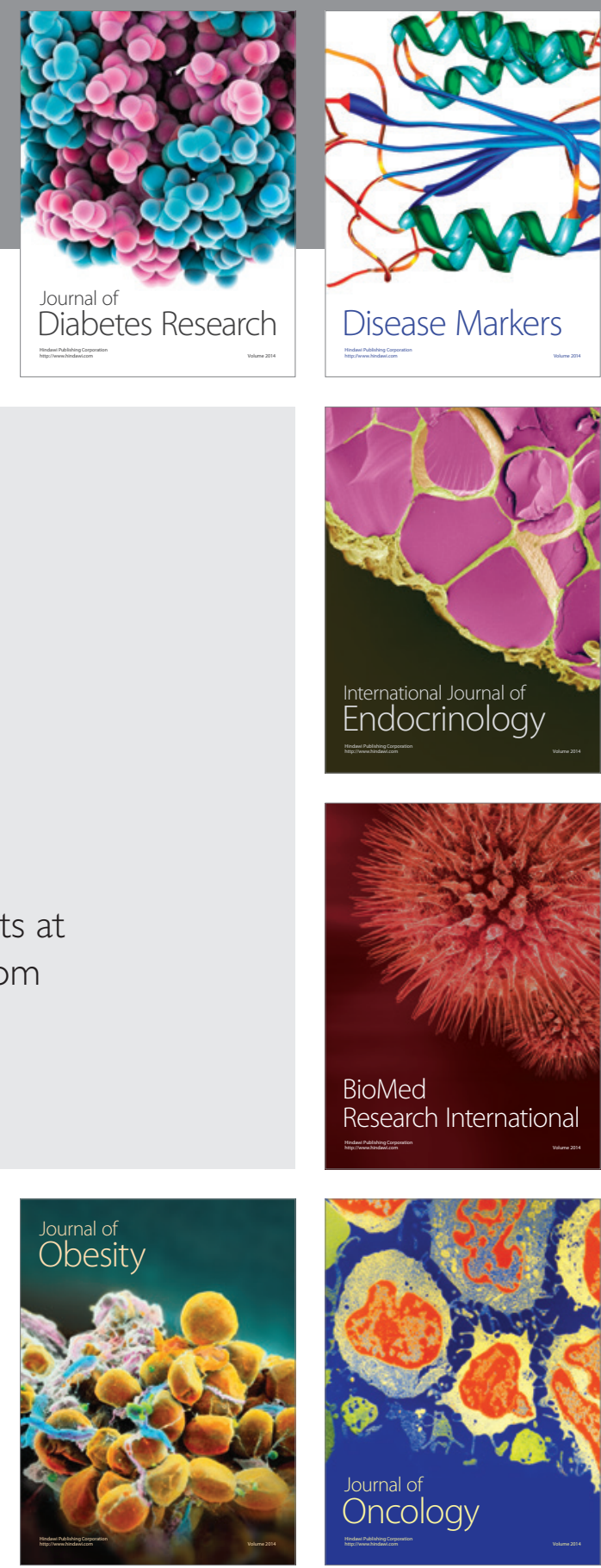

Disease Markers
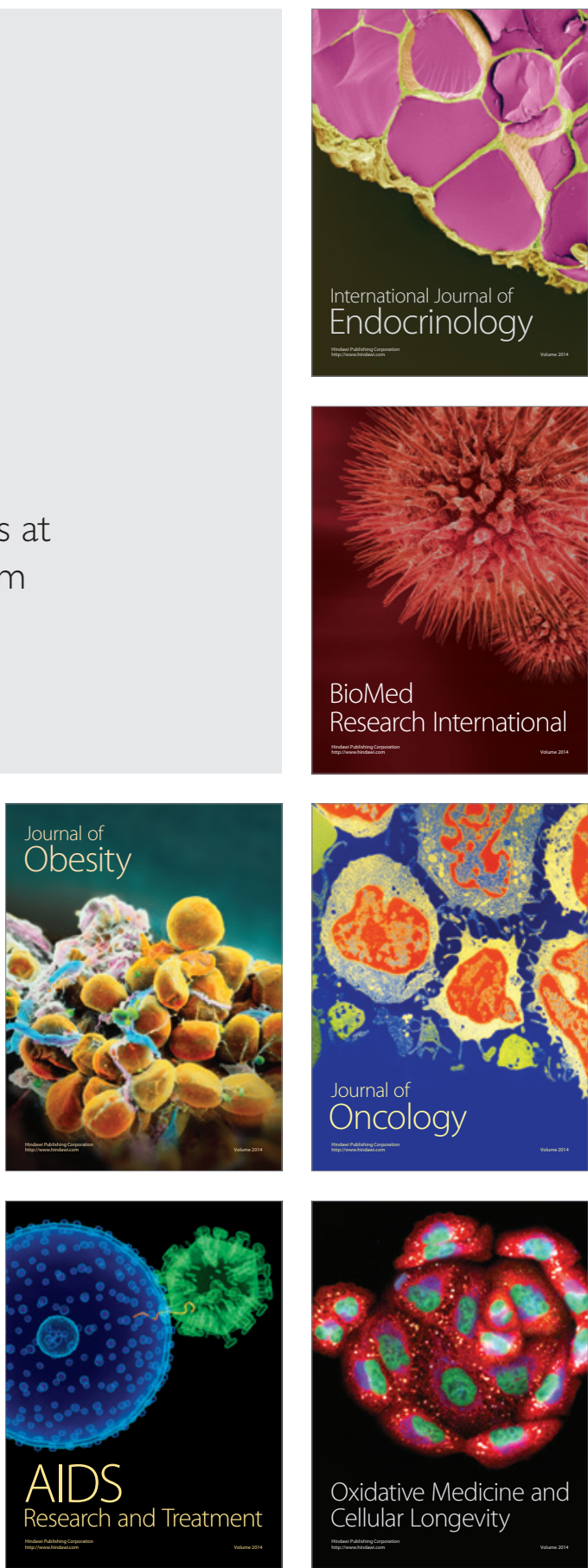